\title{
Variability of the Eurasian Pattern and Its Interpretation by
}

\author{
Wave Activity Flux
}

\author{
By Yasuaki Ohhashi and Koji Yamazaki ${ }^{1}$ \\ Graduate School of Environmental Earth Science, Hokkaido University, Sapporo, Japan
}

(Manuscript received 23 February 1998, in revised form 14 January 1999)

\begin{abstract}
In this study, recent variability of the Eurasian (EU) pattern during 1978-94 and its association with wave activity flux are investigated. The sign of the wintertime EU index abruptly reversed from positive to negative in winter 1988/89, concurrent with the intensified polar vortex. To investigate the mechanism of the EU pattern in detail, we computed the wave activity flux. When the EU index is positive, the Rossby wave propagation appears from North Europe to East Asia directly. When the EU index is negative the wave activity flux is directed more southeastward to the Middle East.

An empirical orthogonal function (EOF) analysis is performed for the wave activity flux to clarify the variations of the Rossby wave propagation over Eurasia. Two dominant modes associated with the EU pattern were detected. The first mode is closely linked with the height anomaly over arctic regions and contributes to a shift in the 1988/89 winter atmosphere. The second mode is related to the other principal teleconnection patterns: the North Atlantic Oscillation (NAO), and Pacific/North American (PNA) patterns.

The appearance of the modes are interpreted in terms of wave forcing to the zonal wind, and the meridional wave propagation of Rossby waves. The Rossby wave with wavenumber three, plays an important role in the zonal wind changes of the first mode. The meridional profile of the zonal wind is consistent with the structure of wave activity flux. The positive feedback between the wave activity and the zonal wind is responsible for the dominance of the first EU mode.
\end{abstract}

\section{Introduction}

It is a well-established fact that meteorological variables undergo low frequency fluctuations with distinctive spatial patterns. These patterns obtained by a correlation analysis are referred to as teleconnections by Wallace and Gutzler (1981). They found several teleconnection patterns in monthly height anomalies during the Northern Hemisphere winter, and summarized the teleconnections at $500 \mathrm{hPa}$ heights ( $c f$. , their Fig. 26). Since Wallace and Gutzler (1981), many studies have been made on low frequency variation in the Northern Hemisphere winter atmosphere (e.g., Horel, 1981; Esbensen, 1984; Hsu and Wallace, 1985; Barnston and Livezey, 1987, among others). The durations of teleconnection patterns vary with their types and

Corresponding author: Yasuaki Ohhashi, Graduate School of Environmental Earth Science, Hokkaido University, 10 Kita, 5 Nishi, Sapporo 060-0810, Japan. Email: ohashi@ees.hokudai.ac.jp

1 Additional affiliation: Frontier Research System for Global Change, Tokyo, Japan.

(C) 1999, Meteorological Society of Japan seasons. Further, it is known that some of these patterns show a decadal-scale variation.

Teleconnection patterns can be divided into two groups (Blackmon et al., 1984). Geographically fixed, north-south dipole patterns straddling a major jet exit regions over the ocean define the first group. The Eastern Atlantic, Western Atlantic and Western Pacific patterns are in this group. The Pacific part of the Pacific/North American (PNA) pattern also belongs to this group. This group of patterns exhibits the change of jet intensity. Wavetrain patterns orientating eastward or southeastward define the second group. The southeastward propagating part of the Eastern Atlantic pattern, PNA and Eurasian (EU) patterns are in this group. Horel and Wallace (1981) suggested that the PNA pattern is induced by the Rossby wave wavetrain from the equatorial Pacific to North America. The cause of these teleconnections are theorized as the Rossby wave propagations, along a great circle (Hoskins and Karoly, 1981). The EU pattern, one of the second group, is identified as a three-center pattern extending from North Europe to East Asia. Since one of 
the three centers of action is located in East Asia, the variability of the EU pattern influences climate over Japan in winter. Barnston and Livezey (1987) found two types of the EU patterns from a rotated empirical orthogonal function (R-EOF) analysis on the monthly mean $700 \mathrm{hPa}$ height fields. There are many studies on the PNA pattern (e.g., Trenberth et al., 1998; Lau and Nath, 1996 among others), whereas studies focused on the EU pattern are few.

Decadal variations in the global atmosphereocean system have lately attracted considerable attention. Recent remarkable decadal shifts had occurred in the $1976 / 77$ and $1988 / 89$ winters. The dominant feature in the $1976 / 77$ shift is that $\mathrm{El}$ Niño in the equatorial Pacific had appeared more frequently than before. Concomitantly, an Aleutian low developed and its center moved eastward from its normal position (e.g., Trenberth, 1990; Nitta and Yamada, 1989).

In the 1988/89 winter, a shift occurred in the midand high-latitude atmospheric circulations. Walsh et al. (1996) found that the sea level pressure over the Arctic decreased abruptly. Tanaka et al. (1996) also found an intensification of the polar vortex over the Arctic since 1988. In contrast with the decrease in the pressure field over the Arctic, the pressure field over the mid-latitude had increased. Trenberth and Hurrel (1994) investigated decadal variations in the North Pacific sea level pressure. They showed increased sea level pressure over the North Pacific since 1988/89, which was associated with the weaker Aleutian low. Kodera et al. (1996) applied an empirical orthogonal function (EOF) analysis to $50 \mathrm{hPa}$ height field. They suggested that the strength of the polar vortex in the stratosphere was closely linked with the propagation of the Rossby wave in the troposphere. The pattern in the troposphere and the lower stratosphere shown in their Fig. 1 is named the Polar region/Europe-Asia (PEA) pattern. Furthermore, Koide and Kodera (1997) used a singular value decomposition (SVD) analysis for the $500 \mathrm{hPa}$ and $50 \mathrm{hPa}$ height fields, and SST to extract the dominant interannual-interdecadal variability. The first mode of the SVD between $500 \mathrm{hPa}$ height and SST, which is almost identical to the second mode between $500 \mathrm{hPa}$ height and $50 \mathrm{hPa}$ height, is related to El Niño and the 1977 climate change. On the other hand, the second mode between $500 \mathrm{hPa}$ and SST, associated with the first mode between $500 \mathrm{hPa}$ height and $50 \mathrm{hPa}$ height, represents variability in the strength of the winter polar vortex. This mode is related to the abrupt shift in 1989, and the pattern at $500 \mathrm{hPa}$ seems to contain the EU pattern.

Watanabe and Nitta (1999) indicated that height patterns associated with the shift in 1989 could be explained by the linear combination of the North Atlantic Oscillation (NAO), PNA and EU patterns.
They investigated the relation between atmosphere and land surface climate conditions by an analysis of snow cover derived from NOAA satellites. They showed a remarkable decrease of snow cover in eastern Eurasia in autumn, which precedes the 1989 atmospheric shift. They suggested that the snow anomalies in eastern Eurasia might play an important role in the following winter. Figure 1 shows the difference of 5-year mean wintertime geopotential height at $500 \mathrm{hPa}$ before and after the shift (similar to Fig. 1 of Watanabe and Nitta, 1999). We can confirm the intensification of the polar vortex and the negative phase of EU pattern in Fig. 1.

Thompson and Wallace (1998) showed that the leading EOF of wintertime sea-level pressure in the Northern Hemisphere is strongly coupled to surface air temperature fluctuations over the Eurasian continent. This pattern is similar to the PEA and also is coupled to fluctuations at the $50 \mathrm{hPa}$ height. They named it the Arctic Oscillation (AO). The AO has a zonally symmetric character near the surface and at $50 \mathrm{hPa}$ while the EU-like pattern is evident at $500 \mathrm{hPa}$. We consider that the PEA and the AO are essentially the same pattern.

From the above-mentioned studies, the EU pattern seems to be the most essential ingredient for the PEA or AO pattern and plays an important role in decadal variability of the Northern Hemisphere wintertime circulation. In this study, we will briefly examine the long-term variability of the EU pattern. In the main part of this study, we try to answer the following questions:

- What is the EU pattern?

- Why is the $\mathrm{AO}(\mathrm{PEA})$ mode predominant?

These problems are discussed in terms of the wave activity and its interaction with the mean flow by using objective analysis data. The cause of the decadal variability is not discussed here.

In Section 2, the data used in this study are described. In Section 3, results are presented. First, we briefly show the variability of the EU pattern. The EOF analysis of wave activity fluxes show the two distinct EU modes. In the main part of Section 3 , the reason for the existence of the EU patterns is investigated from the viewpoint of interaction with zonal-mean zonal winds. The wave forcing to the zonal-mean zonal wind associated with those modes, are investigated using the Eliassen-Palm flux. The meridional wave propagation theory is applied to interpret Rossby wave propagation. The long-term variations of two EU modes are also presented. In section 4 , concluding remarks are provided.

\section{Data}

The data used in this study are derived from the twice-daily objective analysis data from 1978 


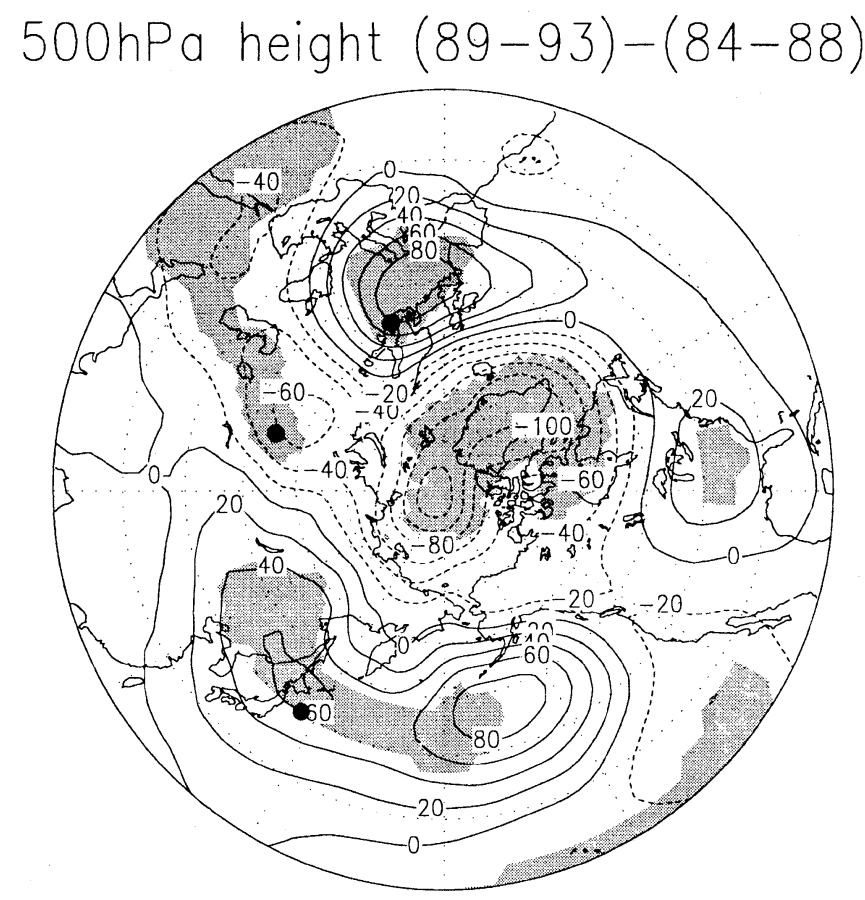

Fig. 1. $500 \mathrm{hPa}$ geopotential height difference for wintertime (DJF) mean from 1989 to 1993 minus that from 1984 to 1988. The three heavy dots denote the centers of the EU pattern defined by Wallace and Gutzler (1981). The $95 \%$ significance levels are shaded.

through 1994 from the U.S. National Meteorological Center (NMC, presently known as the National Centers for Environmental Prediction, NCEP). We compiled the data to the monthly mean data, and used the sixteen winters from 1978/79 through 1993/94. The NMC data has a horizontal resolution of $2.5^{\circ} \times$ $2.5^{\circ}$ in latitude and longitude. A winter season was defined as December, January, and February. We also used the monthly mean $500 \mathrm{hPa}$ geopotential height data at $5^{\circ} \times 5^{\circ}$ grids in the Northern Hemisphere from 1946/47 through 1995/96 provided by the Japan Meteorological Agency (JMA) to analyze long-term variability. From now on, the year for winter denotes the year of January. Namely, 1947 winter means the period from December 1946 to February 1947.

\section{Results}

\subsection{Long-term variability of the EU pattern and the polar vortex}

Wallace and Gutzler (1981) defined the EU pattern index as follows,

$$
\begin{aligned}
\mathrm{EU}= & -\frac{1}{4} \mathrm{Z}^{*}\left(55^{\circ} \mathrm{N}, 20^{\circ} \mathrm{E}\right)+\frac{1}{2} \mathrm{Z}^{*}\left(55^{\circ} \mathrm{N}, 75^{\circ} \mathrm{E}\right) \\
& -\frac{1}{4} \mathrm{Z}^{*}\left(40^{\circ} \mathrm{N}, 145^{\circ} \mathrm{E}\right),
\end{aligned}
$$

where the symbol $\mathrm{Z}^{*}$ denotes a normalized monthlymean height anomaly at the grid point. Because base grid points at both ends are $125^{\circ}$ apart in longitude, the zonal wavenumber of the EU pattern is roughly 3 .

We calculated the winter mean (three-month mean for December, January and February) of the EU index from 1947 winter to 1996 winter based on the JMA data (Fig. 2a). From the late 1970's to 1988 winter, the EU index remained positive or near zero except for 1979. Its sign has changed from positive to negative since the 1989 winter, and lasted until the 1994 winter. The negative value indicates that the phase in the height anomaly field is plus (in North Europe) -minus (in central Eurasia) -plus (in East Asia). This result is consistent with recent warmer winters in East Asia including Japan, and related to the atmospheric circulation shifts in the Northern Hemisphere in winter 1989. Another negative period is found in the early 1970's.

Because the AO (PEA) has a large fluctuation over the polar region, we define the polar cap (PC) index as the normalized areal mean $500 \mathrm{hPa}$ height anomaly field northward of $75^{\circ} \mathrm{N}$, which indicates the strength of the polar vortex. The long-term variability of the PC index is shown in Fig. 2b. The PC index also shows the decadal shift since 1989 - the value in 1989 dropped to the lowest one from the positive value in 1988 (also see Fig. 1). The EU and $\mathrm{PC}$ indices seem to have a positive correlation. After the 1970's, in particular, the two indices change synchronously. The correlation coefficient between both 

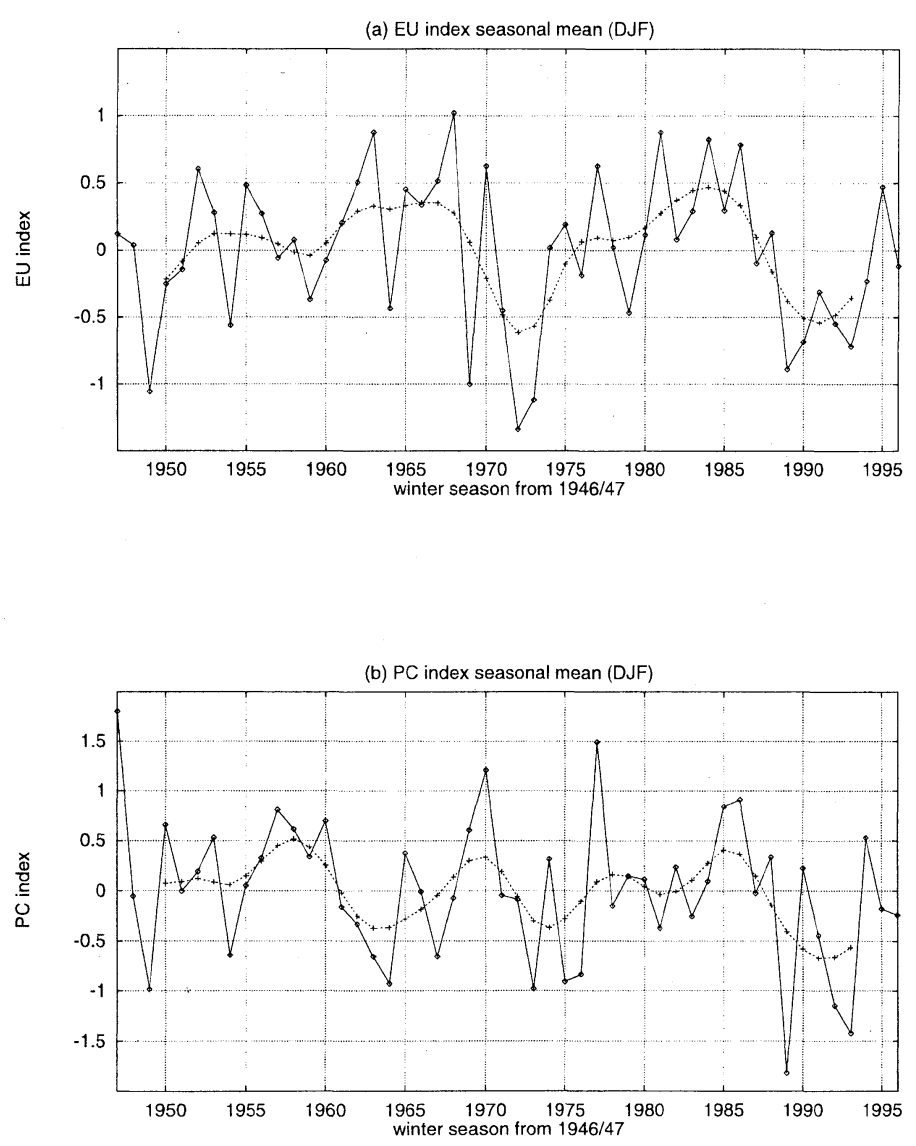

Fig. 2. Long term variability of (a) the EU index and (b) the PC index (solid line). The dashed lines represent the indices smoothed with a low-pass filter with seven-points weight $(1,3,5,6,5,3$, and 1) to remove fluctuations with periods less than four years. These indices are defined in the text.

indices during 50 years is 0.36 , which is a $95 \%$ significance level. The correlation coefficient since 1970 is 0.55 , which is a $99 \%$ significance level. From the low-passed data, both indices exhibit decadal variations. It is also noted that the PC index shows the lowest values in the early 1990's in a decadal variation, while the EU index lowest values are in the early 1970's. The power spectra of the EU and PC indices, using the Blackman-Tukey method, show that the EU index and the $\mathrm{PC}$ index have spectral peaks around 20 years (16-30.8 years) and 10 years (8.9-11.4 years), respectively (not shown). Additionally, both indices have spectral peaks at 2 year periods.

\subsection{Wave propagation associated with the EU pat- tern}

Hoskins and Karoly (1981) have theorized the mechanism of the teleconnections in the height field as Rossby waves, propagating along a great circle. Later, Plumb (1985) defined the three dimensional wave activity flux for stationary waves. It is approximately a good indicator of the energy propagation of a stationary Rossby wave. To examine the wave propagation associated with the EU pattern, we compute the wave activity flux based on Plumb (1985).

Figure 3 shows the composite maps of the wave activity fluxes at $500 \mathrm{hPa}$ when the EU index is positive (a) and negative (b). We used the NMC data for these composites, because wave activity flux cannot be calculated by $500 \mathrm{hPa}$ height alone. The positive composite consists of years 1981, 1984, and 1986, while the negative consists of years 1989, 1990, and 1993. The positive years are before the decadal change of the EU index, and the negative years are after it.

The common features in both composites are upward and southeastward propagation from the North Atlantic, and upward and eastward propagation from East Asia to the west-coast of the USA. In the positive composite, besides the southeastward propagation of the wave activity flux, the flux from the Norwegian Sea propagates zonally over the Eurasian continent, is reinforced over West Siberia and excited again at East Asia. The result suggests that the Rossby wave propagation extended zonally in the positive case. In the negative case flux 
(a) EU+,500hPa,DJFmean

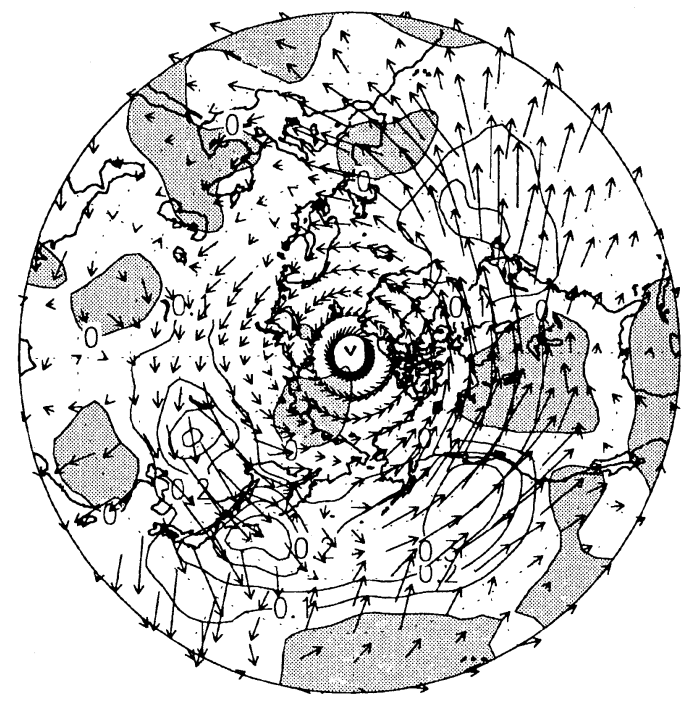

(b) EU-,500hPa,DJFmean

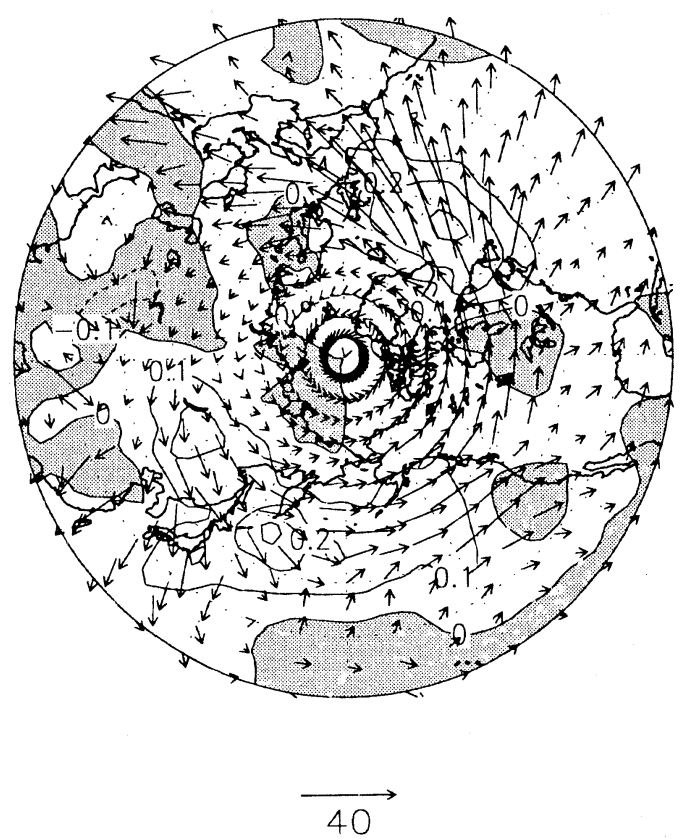

Fig. 3. Composite maps of the wave activity flux on the $500 \mathrm{hPa}$ height field when the EU index is (a) positive: 1981, 1984, 1986, and (b) negative: 1989, 1990, 1993. (c) The difference map between the positive and the negative cases (i.e., (b) minus (a)). The arrows show the horizontal components and the contours show the vertical components. Negative values are shaded. Units in both figures are $\mathrm{m}^{2} \mathrm{~s}^{-2}$.

activity over the Norwegian Sea direct east-southeastward, and flux propagating over the Eurasian continent is not clear. The upward component of the flux over the North Atlantic is stronger than in the positive case. The wave flux from the North Atlantic propagates more southward and southeastward through western Europe. The difference map (Fig. 3c) clearly shows the above-mentioned feature 


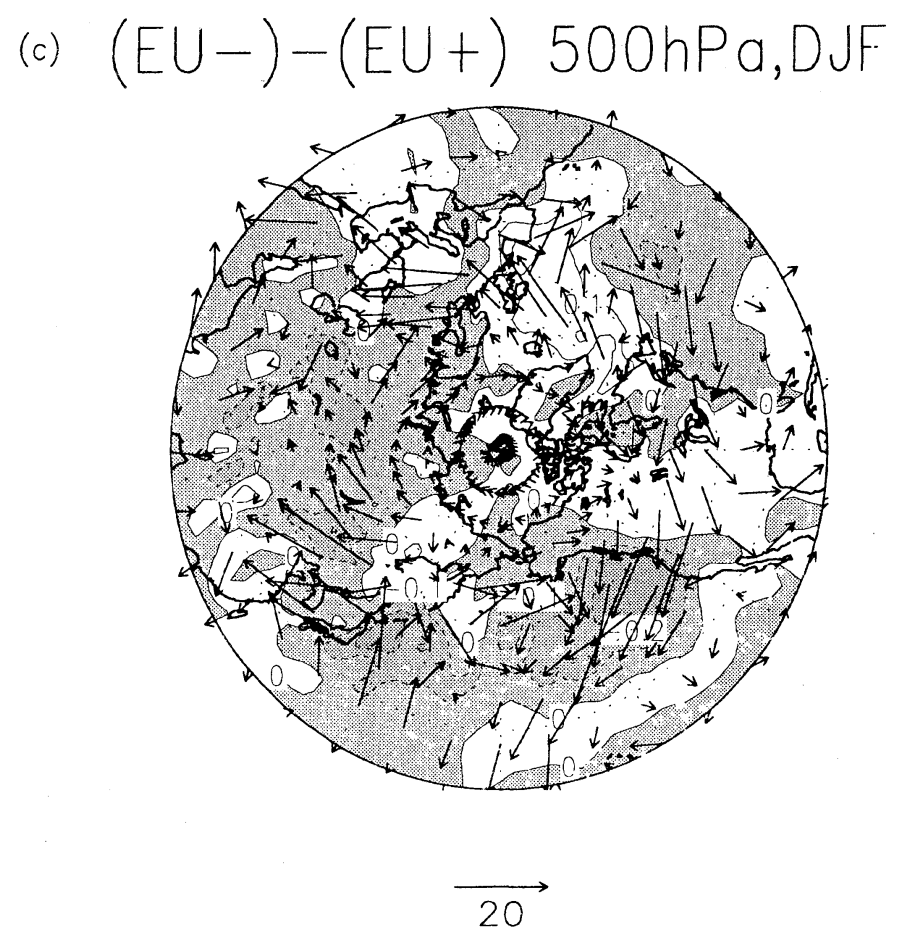

Fig. 3. (Continued)

of the EU pattern. In the negative case, the generation of a Rossby wave is largely enhanced over the North Atlantic, especially over its northeastern region. The wave activity disperses more southeastward. Over Eurasia, on the other hand, the generation of a Rossby wave is reduced. This implies that the stationary eddy field over Eurasia becomes weak, and the flow is more zonal in the negative case.

Another important feature is seen over the $\mathrm{Pa}$ cific. In the negative case, the upward flux over the northeastern Pacific is greatly reduced. Moreover, the horizontal fluxes from low latitudes to middle latitudes near the dateline almost disappear, though the fluxes are found in the positive case.

\subsection{EOF analysis of wave activity flux}

The composite analysis of wave activity flux in the previous subsection suggests that the EU pattern is understood as the changes in the generation and propagation of the Rossby wave. Therefore, we further investigate the variation of wave activity flux. To extract the prominent pattern of the wave activity flux variability, an EOF analysis is applied to three dimensional wave activity fluxes. Because we focus on the EU pattern, the analysis region is limited from the North Atlantic to East Asia, $60^{\circ} \mathrm{W}-$ $150^{\circ} \mathrm{E}$ and $30^{\circ} \mathrm{N}-70^{\circ} \mathrm{N}$. The horizontal resolution is reduced to $10^{\circ}$ longitude by $5^{\circ}$ latitude. The number of grid points is 198 in this region, and thus the matrix size is $198 \times 3=594$. Eigenvectors are calculated from the correlation matrix based on the winter-mean fields.

Figure 4 shows the distribution of the first and second eigenvectors and corresponding time series. The percentages of variances explained by these EOFs are 20.9 and $12.6 \%$, respectively. The third mode makes up $9.7 \%$ of the total variance, and is not discussed further since it exhibits negligible correlation with the EU pattern.

The first mode is discussed first. The vertical component (contours in Fig. 4a) shows positive values over the North Atlantic, west Europe and the Mediterranean Sea, while negative values are seen over most of Eurasia and Japan. This pattern represents the seesaw in generating a stationary Rossby wave between the Atlantic region and the Eurasian continent. Horizontal components of this EOF exhibit a southeastward flux pattern propagating from the North Atlantic toward Europe and the Mediterranean. Whereas, over the eastern Eurasian continent, the flux directs southwestward. The flux generally directs equatorward, and the magnitude of equatorward flux is large around $55^{\circ} \mathrm{N}$. The score has an increasing trend in addition to a decadal change since 1989. After 1989, the scores produce positive values except for 1994. Table 1 shows the correlation coefficients between the score and the EU index, and also between other teleconnection indices and the leading two EOFs. The coefficient between the first score and the EU index is -0.42 , which is significant at the $90 \%$ significance level. On the 


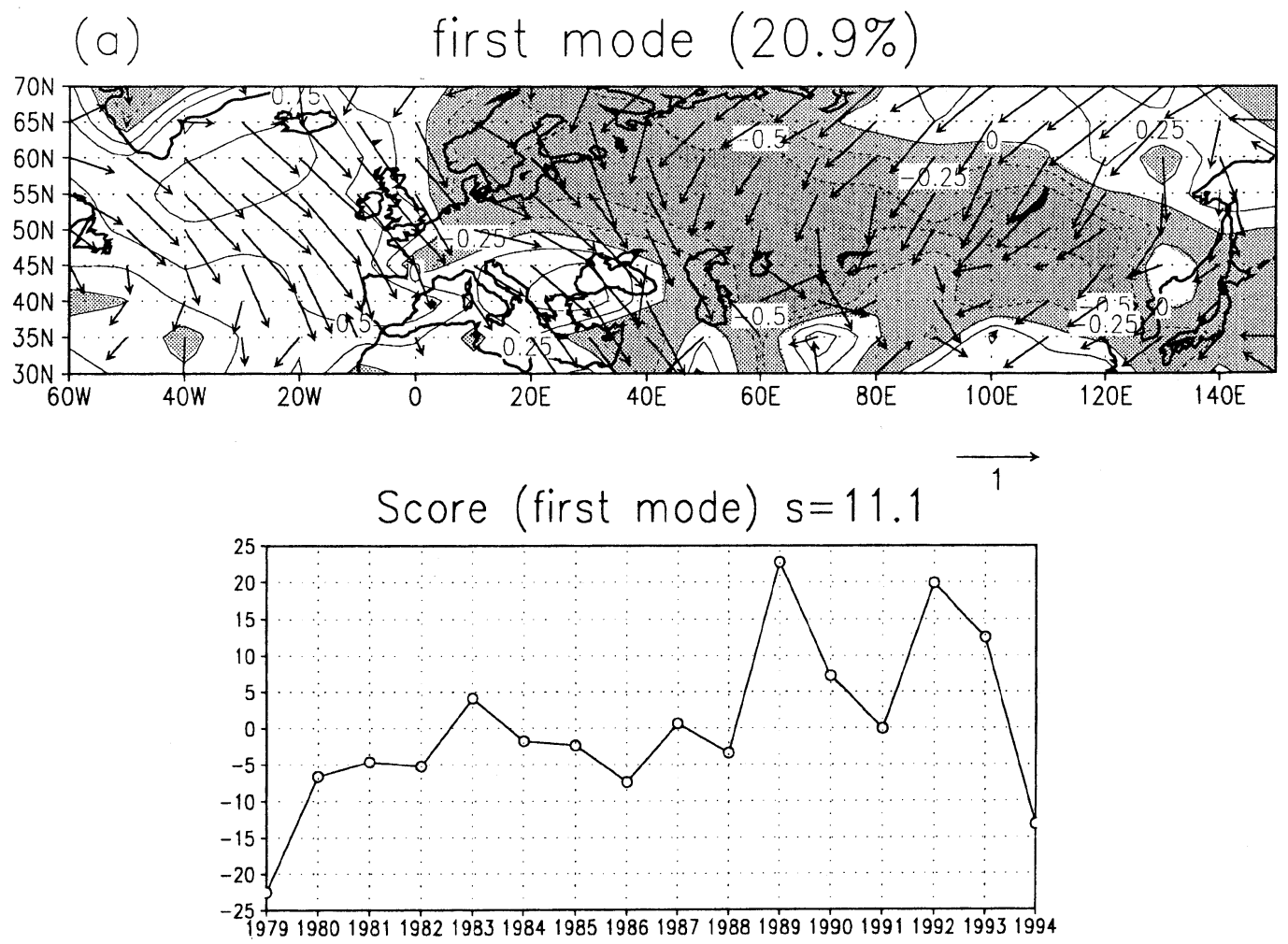

(b) $\quad$ second mode $(12.6 \%)$

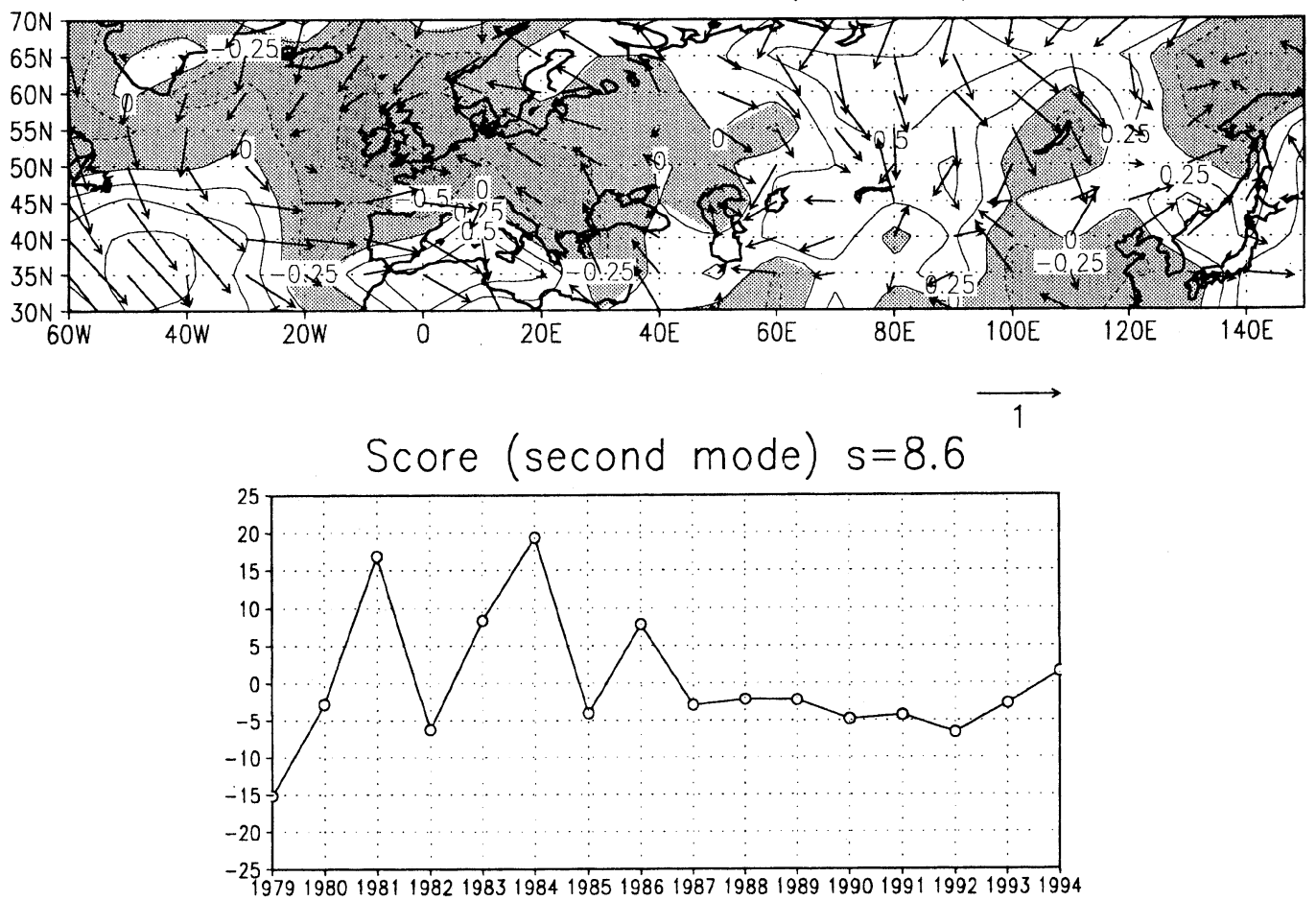

Fig. 4. Spatial patterns of the eigenvector and corresponding scores for (a) the first mode and (b) the second mode. The eigenvectors are multiplied by the standard deviation of scores. The percentage variance of each eigenvectors is shown at the top of each panel. S indicate the standard deviation of scores. The arrows indicate horizontal components and the contours indicate vertical components. Negative values are shaded. 
Table 1. Correlation coefficients between the scores of EOF modes and the teleconnection indices for winter seasons. The symbols * and ** denote significant values at $95 \%$ and $99 \%$ levels, respectively.

correlation coefficient (3-month mean)

\begin{tabular}{cccl}
\hline & EU & PNA & NAO \\
\hline 1st mode & -0.42 & -0.05 & $0.67^{* *}$ \\
2nd mode & $0.76^{* *}$ & $0.63^{*}$ & 0.44 \\
\hline
\end{tabular}

other hand, the correlation coefficient between the score and the PNA index defined by Wallace and Gutzler (1981), and the NAO index ${ }^{2}$ (Hurrell, 1995) are -0.05 and 0.67 , respectively.

The vertical component of the second EOF (contours in Fig. 4b) shows positive values off the east coast of the US, while negative values over Europe centered on Ireland. This is interpreted as a shift of the wave generation region in northeast-southwest direction over the North Atlantic. The vertical flux over Siberia is positive, which implies that the southwestward shift of the wave generation over the North Atlantic accompanies the generation of the wave over Siberia. For the horizontal components, the flux propagating southeastward in the North Atlantic is located more southward than that of the first mode. The flux at the west end of the domain is extremely strong. It suggests that the flux located west of this region, the western Atlantic and North America, has an effect on the pattern that appeared in this mode. Over Siberia, large southward fluxes appear to be found. Scores of the second EOF show large variability before 1986, whereas they exhibit small variability after 1987 . The correlation coefficient between the score and the EU index is 0.76 , which is significant at the $99 \%$ significant level. Additionally, the correlation coefficient between the score and the PNA and NAO index (Table 1) are 0.63 and 0.44 respectively.

As described above, we found two dominant modes of variability in wave activity fluxes over the North Atlantic and the Eurasian continent. The time-series of the scores indicate that both modes are related to the EU pattern, though the second mode shows stronger correlation with the EU pattern. Both of them exhibit the equatorward flux pattern and high correlations with the NAO. The first mode is closely related to the shift in 1989 while the second mode is related to the PNA. In the next subsection, the geopotential height anomalies associated with these two modes are investigated.

2 The NAO index is defined as the difference of normalized sea level pressures between Lisbon, Portugal, and Stykkisholmur, Iceland. In this paper, we used $500 \mathrm{hPa}$ data at $\left(40^{\circ} \mathrm{N}, 10^{\circ} \mathrm{W}\right)$ and $\left(65^{\circ} \mathrm{N}, 20^{\circ} \mathrm{W}\right)$.

\subsection{Geopotential height patterns associated with the} EOF modes

To obtain the anomaly patterns of the height anomaly field associated with the EOFs of wave activity fluxes, composite maps are made for the winter-mean $500 \mathrm{hPa}$ height anomaly field over the Northern Hemisphere, based on the EOF scores shown in Fig. 4. Three winters are selected for each category.

Figure 5 shows the composite maps of the height anomaly differences between high score winters and low score winters. The common feature in both patterns is that the EU pattern clearly appears. In the pattern based on the first EOF (Fig. 5a), the negative anomaly appears over the arctic and the North Atlantic regions. The largest negative anomaly is located to the south of Greenland, while the largest positive anomaly is found in central Europe. These anomalies indicate the enhancement of a climatological eddy field which is deviation from a zonal mean field shown in Fig. 6. Thus, the anomaly pattern shown in Fig. 5a agrees with the enhancement of wave activity over the North Atlantic. On the other hand, the negative anomaly over the Ural mountains and the positive anomaly over Siberia indicate the weakening of stationary waves, consistent with the weakening of upward wave activity flux over Eurasia (Fig. 4a).

It is noteworthy that the anomaly pattern shown in Fig. $5 \mathrm{a}$ is quite similar to the anomaly pattern after the 1989 shift (Fig. 1), except that the pattern in the mid-latitude Pacific sector is too weak. This result suggests that the pattern associated with the first mode corresponds to the recent decadal shift in atmospheric circulation in the Northern Hemisphere winter.

The pattern based on the second EOF (Fig. 5b) shows the north-south dipole pattern over the North Atlantic, which resembles the NAO. In the positive phase of this pattern, the wave activity off Newfoundland is enhanced. But, is suppressed to the northeast. Over Eurasia, the large positive anomaly is found over the Ural mountains and a small negative anomaly over Japan. This pattern indicates the enhancement of a stationary wave, which is associated with enhancement of the upward wave activity flux over Siberia. It is also noted that large negative anomalies are prominent in the Pacific sectors, and positive ones are located over North America (Fig. 5b), which is reminiscent of the PNA pattern and of the enhancement of a climatological eddy field. However, no characteristic pattern appears over the arctic region.

We showed two anomaly patterns composed from two dominant modes of wave activity flux variation over Eurasia, both of which are related to the EU pattern. The centers of action for these two patterns are located near each other. Therefore, the correla- 

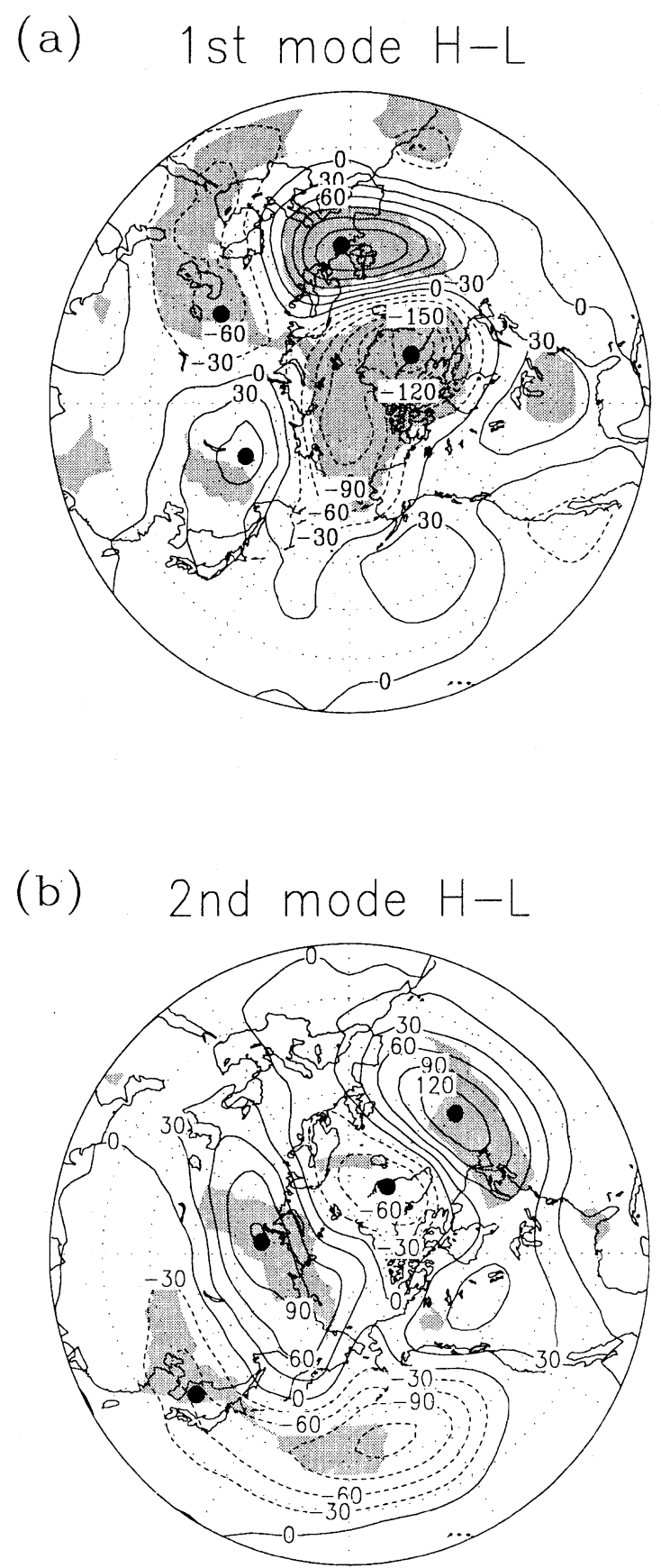

Fig. 5. Composite maps of $500 \mathrm{hPa}$ height anomaly differences between three winters with EOF high score and those with low score. (a) Differences associated with the first EOF. The high composite years comprise 1989, 1992, 1993 while the low composite years comprise 1979, 1986, 1994. (b) As in (a), but for the second EOF. The high and low composite years comprise 1981, 1983, 1984 and $1979,1982,1992$, respectively. The contour interval is $30 \mathrm{~m}$. Positive values are indicated by solid lines, and negative values are indicated by dashed lines. The $90 \%$ significance level are shaded. The heavy dots denote the centers of the EU1 and EU2 patterns we defined.

tion technique used by Wallace and Gutzler (1981) could obtain only one EU pattern. The spatial correlation coefficient between these two anomaly patterns (Fig. 5a and Fig. 5b) is 0.09 . This negligible correlation coefficient strongly suggests that these two patterns, expressed in the composite height field, are independent of each other. The anomaly pattern shown in Fig. $5 \mathrm{~b}$ is more similar to the EU pattern defined by Wallace and Gutzler (1981), which has no signal over the arctic region ( $c f$. , their Fig. 25). Barnston and Livezey (1987) also obtained two EU-like patterns from the rotated EOF analysis 


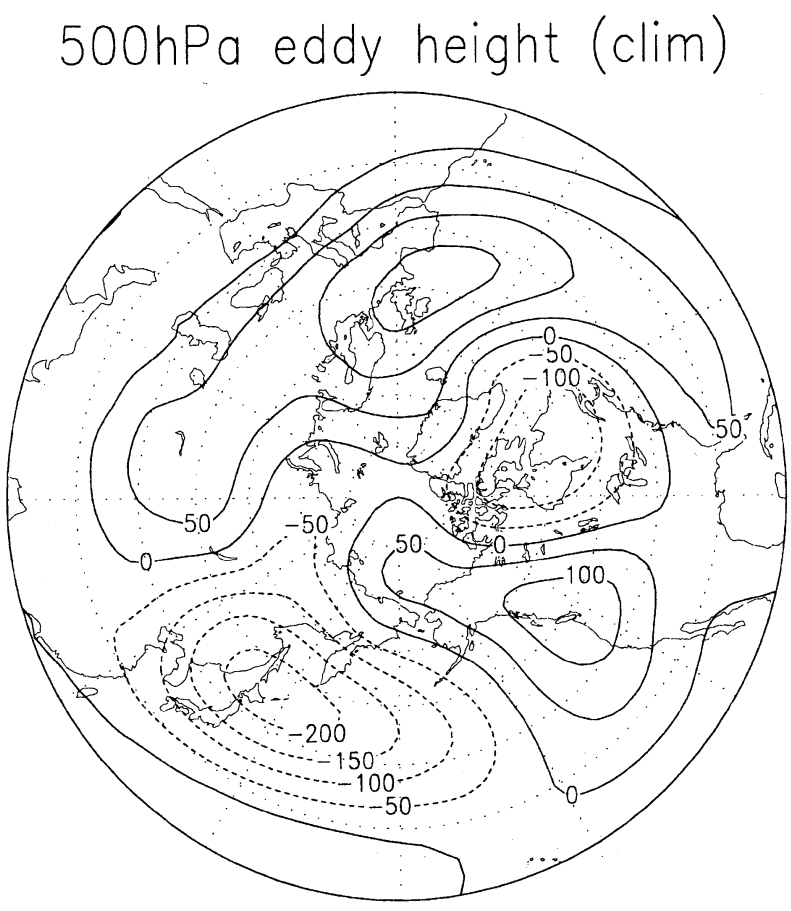

Fig. 6. Climatological $500 \mathrm{hPa}$ eddy height for DJF averaged during 1979-1994.

of monthly mean $500 \mathrm{hPa}$ height data. Among the EU patterns, the type 1 in January is similar to our pattern based on the second EOF, while the type 2 in January is similar to our first pattern, though the comparison is not complete.

\subsection{E-P flux and wave forcing}

In this subsection, we examine the EU-related wave forcing to the zonal mean wind due to stationary waves. Figure 7 shows the zonal-mean zonal wind differences between the high score composite, and the low score composite. In the difference field based on the first EOF (Fig. 7a), the structure is quasi-barotropic. The zonal wind is stronger north of $\sim 50^{\circ} \mathrm{N}$ in the high composite. The reverse is true between $25^{\circ}$ and $50^{\circ} \mathrm{N}$. This means that the polar vortex is stronger in the high composite, so that the difference at $67.5^{\circ} \mathrm{N}, 50 \mathrm{hPa}$ is as large as $10 \mathrm{~ms}^{-1}$. This zonal wind pattern is almost the same as that of $\mathrm{AO}$ (PEA).

To interpret the zonal wind changes in terms of the wave-mean flow interaction, we calculate the Eliassen-Palm (E-P) flux of 3-month mean data, and composite using the EOF scores. When the zonal mean is applied to the three dimensional wave activity flux, it reduces to the E-P flux. Figure 8 shows the differences in the E-P cross sections between the high score winters and the low score winters, as in Figs. 5 and 7.

The difference field associated with the first EOF (Fig. 8a) is discussed first. In the lower troposphere, the upward wave propagation of high score winters is enhanced around $60^{\circ}-70^{\circ} \mathrm{N}$, and reduced equatorward of $55^{\circ} \mathrm{N}$ more than low score winters. In the middle and upper troposphere and the lower stratosphere, equatorward propagation is notable. At $500 \mathrm{hPa}$, equatorward flux is apparent, consistent with the eigenvector pattern in Fig. 4a. In the stratosphere, upward flux is reduced. In high score winters, the easterly wave forcing is much weaker at approximately $60^{\circ} \mathrm{N}$, indicating that the westerly wind deceleration is weaker. At south of $55^{\circ} \mathrm{N}$, the easterly wave forcing becomes stronger. Thus the westerly wind is decelerated more there than at lower cases.

To examine the contribution of each planetaryscale wave, the E-P flux calculations were made for wavenumbers 1, 2, 3 and composite profiles made for each mode (Fig. 9). In the difference field associated with the first EOF (Figs. 9a-9c), compared with the total E-P flux and $\nabla \cdot \mathbf{F}$ (Fig. 8a), southward E-P flux in the mid- and upper-troposphere is notable in wavenumber 3 . Downward flux in the lowertroposphere at $30^{\circ} \mathrm{N}-50^{\circ} \mathrm{N}$ is apparent in wavenumber 2 , and also at $50 \mathrm{hPa}$ at about $60^{\circ} \mathrm{N}-70^{\circ} \mathrm{N}$ in wavenumbers 1 and 3 . Seen in $\nabla \cdot \mathbf{F}$ patterns in wavenumber 3 , mid-troposphere easterly wave forcing is weaker at $\sim 65^{\circ} \mathrm{N}$ and the opposite sense at about $45^{\circ} \mathrm{N}$. These results indicate that the main contribution of the wave forcing is due to wavenumber 3 components for the first EOF. Although the E-P flux and $\nabla \cdot \mathbf{F}$ are calculated by using zonal mean values, the results are consistent with our EOF re- 


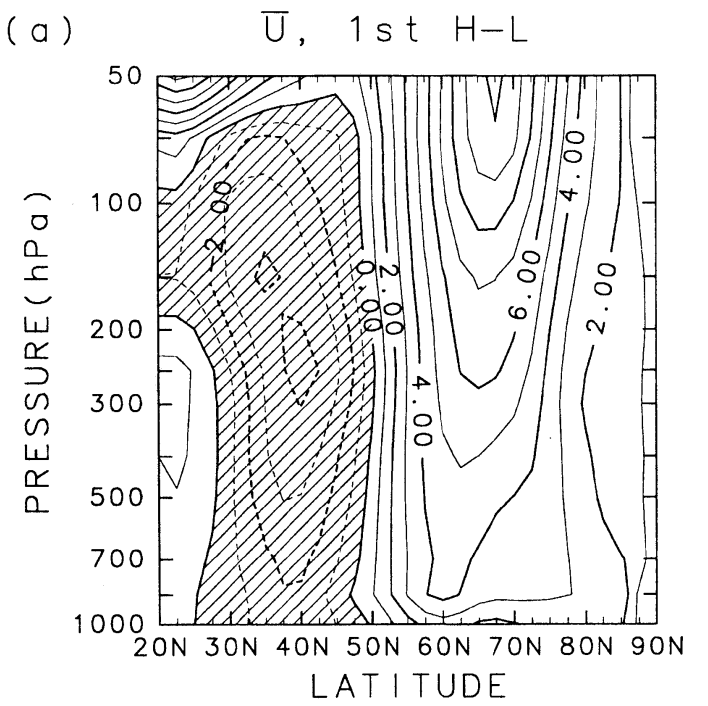

CONTOUR INTERVAL $=1.000 E+00$

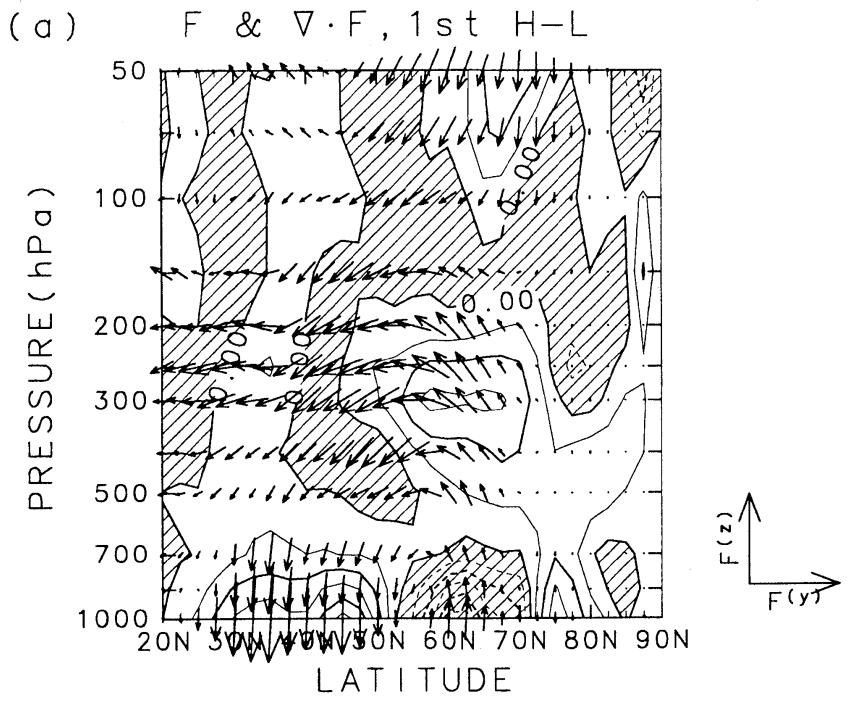

XUNIT $=1.000 E+00, \quad$ YUNIT $=1.000 E+00$

CONTOUR INTERVAL $=1.000 E+00$

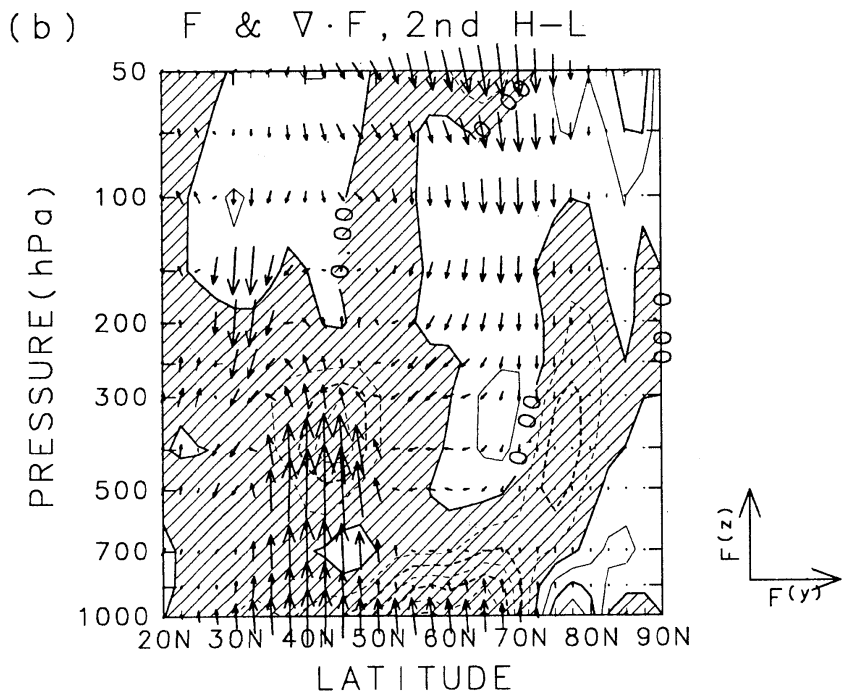

XUNIT $=1.000 E+00, \quad$ YUNIT $=1.000 E+00$

CONTOUR INTERVAL $=1.000 E+00$

Fig. 8. As in Fig. 5, except for differences in the Eliassen-Palm (E-P) cross section. Contours represent acceleration of the mean flow due to the E-P flux divergences. Contour interval is $1.0 \mathrm{~ms}^{-1}$ day $^{-1}$. The length of the E-P flux vectors is multiplied by the factor $\exp (z / H)$, where $H$ is the scale height $\left(H=6.98 \times 10^{3} \mathrm{~m}\right)$. Unit vectors over the meridional and vertical components of E-P flux vectors are $1 \times 10^{16} \mathrm{kgms}^{-1}$ and $2.5 \times 10^{13} \mathrm{kgms}^{-1}$, respectively. 
and lower-stratosphere around $60^{\circ} \mathrm{N}$, where easterly wave forcing is weaker in the high score winters than in the low score winters. In the wave decomposition (Figs. 9d-9f), the E-P flux pattern of wavenumber 3 is much smaller than that of wavenumbers 1 and 2. In wavenumber 1 (Fig. 9d) an upward flux is found near $45^{\circ} \mathrm{N}$, and downward flux in the uppertroposphere and lower-stratosphere, which resembles the total E-P flux pattern. Easterly wave forcing is strong in the mid-troposphere between $40^{\circ} \mathrm{N}$ and $50^{\circ} \mathrm{N}$ in wavenumber 1 .

\subsection{Interpretation from meridional wave dispersion}

In the previous subsection, we examined the effect of stationary waves on the zonal wind field. In this subsection, the effect of zonal wind on the wave is examined. To this end, we applied the meridional Rossby wave dispersion theory (Held, 1983). The theory is briefly described below. Following Hoskins and Karoly (1981), we transform the linearized unforced inviscid vorticity equation into Mercator coordinates.

Then the vorticity equation becomes

$$
\hat{u} \frac{\partial}{\partial x}\left(\frac{\partial^{2}}{\partial x^{2}}+\frac{\partial^{2}}{\partial y^{2}}\right) \psi^{*}=-\hat{\beta} \frac{\partial \psi^{*}}{\partial x},
$$

where $\hat{u} \equiv[u] / \cos \phi$ and $\hat{\beta} \equiv \cos \phi(\beta+1 / a \partial[\zeta] / \partial \phi)$ and $\zeta$ is relative vorticity. The symbols [] and ( )* are respectively the zonal average, and the deviation from zonal average.

For wave solutions $\psi^{*}=\operatorname{Re} \tilde{\psi} \exp (i k x)$, we obtain

$$
\frac{d^{2} \tilde{\psi}}{d y^{2}}=\left(k^{2}-\frac{\hat{\beta}}{\hat{u}}\right) \tilde{\psi}
$$

Given a source localized in latitude, zonal wavenumbers $k>k_{s} \equiv(\hat{\beta} / \hat{u})^{1 / 2}$ are meridionally trapped in the vicinity of the source, while wavenumbers $k<k_{s}$ propagate away from the source.

Figure 10 shows the wavenumbers $n_{s}=a k_{s}$ as a function of latitude composed from two EOF modes. The composites are high and low score years of the EOFs shown in Fig. 4. The analysis region is the same in longitude as in the EOF analysis $\left(60^{\circ} \mathrm{W}-\right.$ $\left.150^{\circ} \mathrm{E}\right)$. The left side of the $n_{s}$ line is the area where the meridional propagation of the Rossby wave is possible, while the right side is the trapped area. There is also a trapped area in the low latitude because of the easterly wind.

For the low score composite of the first mode, the wave with the wavenumber 3 is in a trapped area in the region between $50^{\circ} \mathrm{N}$ and $55^{\circ} \mathrm{N}$, whereas for the high score composite, the wave is in a propagating area. This result suggests that the Rossby wave, with the wavenumber 3 from $55^{\circ} \mathrm{N}-60^{\circ} \mathrm{N}$, is trapped and cannot propagate equatorward in the low score case. Therefore, the wavenumber 3 component is forced to propagate eastward around $55^{\circ} \mathrm{N}$ toward the Eurasia continent. Note that the geopotential anomaly pattern over Eurasia has a scale of zonal wavenumber 3 (Fig. 5a). On the other hand, in the high score case, the Rossby wave with wavenumber 3 can propagate equatorward and thus the eastward propagation is reduced over Eurasia. This is consistent with the EOF pattern and the height composite map (Figs. 4a and 5a).

The difference in meridional profile of $n_{s}$ arises from the difference in the meridional profile of zonal wind (Fig. 11). In the high score case of the first mode (Fig. 11a), when the equatorward wave activity flux is strong, the zonal wind to the south of $50^{\circ} \mathrm{N}$ is weaker than in the low score case. The wind is in the opposite sense to the north. Therefore, a sharp jet is formed around $25^{\circ} \mathrm{N}$ in the high score case. Near $50^{\circ} \mathrm{N}$, the meridional gradient of zonal wind becomes weak in the high case. Examining what contributes to the cause of change in the $k_{s}$ profile, it is found that the $\hat{\beta}$ term mainly produces the difference. Change in the meridional gradient of relative vorticity. $\partial[\zeta] / \partial \phi \sim-\partial^{2}[u] / \partial y^{2}$ around $55^{\circ} \mathrm{N}$ is negative in the low score cases, whereas the value in the high score case becomes positive.

From the above analysis and considering wave forcing (Fig. 8 and Fig. 9c), the following interpretation can be made. In the high score case, wave activity over the North Atlantic is enhanced and it propagates equatorward. It modifies the zonal wind by easterly wave forcing, which further produces the favorable zonal wind profile for the meridional (equatorward) propagation, and thus suppresses the eastward propagation and wave generation over Eurasia. On the contrary, when the wave activity over the North Atlantic is suppressed, the zonal wind profile is modified and is favorable for eastward propagation of the wavenumber 3 wave.

In the composite of the second mode, the Rossby wave with the wavenumber 3 can propagate in the high score case near $50^{\circ} \mathrm{N}$ and $55^{\circ} \mathrm{N}$. In the low score, it is difficult for the wave to propagate equatorward because of a dip between $50^{\circ} \mathrm{N}$ and $55^{\circ} \mathrm{N} . \partial[\zeta] / \partial \phi \sim$ $-\partial^{2}[u] / \partial y^{2}$ in the high case becomes positive, and in the low case becomes negative in this region.

Ting et al. (1996) suggested that stationary waves in the Northern Hemisphere are closely linked with the zonal flow variability except for the tropical region, which is consistent with our results. They found that the regression analysis based upon the zonal flow variability, explains up to $30 \%-40 \%$ of the local seasonal variance of regional eddy heights.

The changes in zonal wind profile and the equatorward wave activity flux are consistent both from the viewpoints of wave-zonal flow interaction (Figs. 8 and 9) and from the viewpoint of meridional wave dispersion theory (Fig. 10). Namely, the wavezonal flow interaction can be interpreted as follows. 


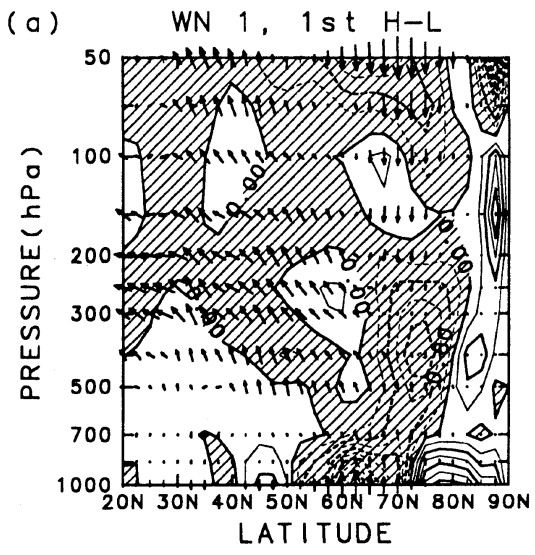

XUNIT $=6.667 E-01$, YUNIT $=6.667 \mathrm{E}-01$

CONTOUR INTERVAL $=4.000 E-01$

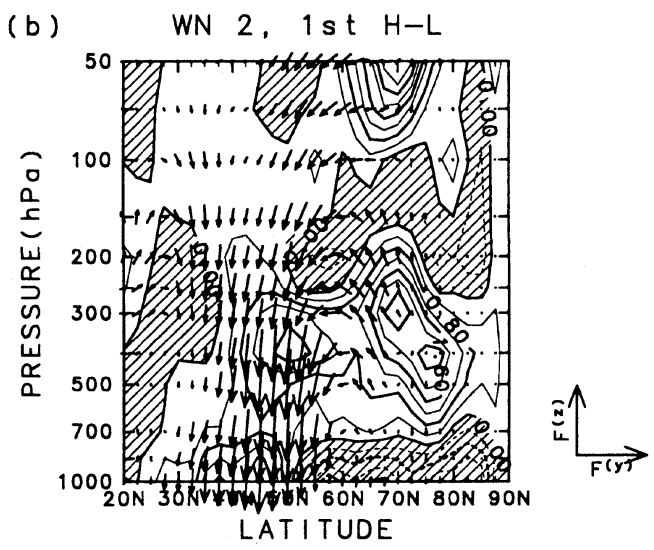

XUNIT $=6.667 \mathrm{E}-01$, YUNIT $=6.667 \mathrm{E}-01$

CONTOUR INTERVAL $=4.000 E-01$

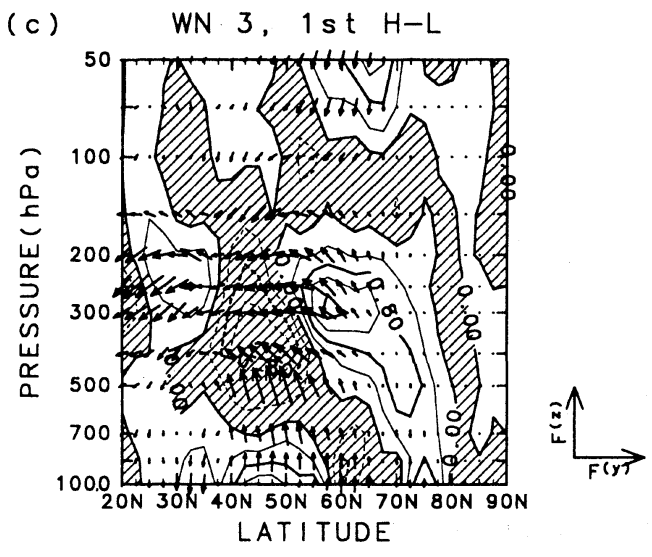

XUNIT $=6.667 E-01, Y U N I T=6.667 E-01$

CONTOUR INTERVAL $=4,000 E-01$

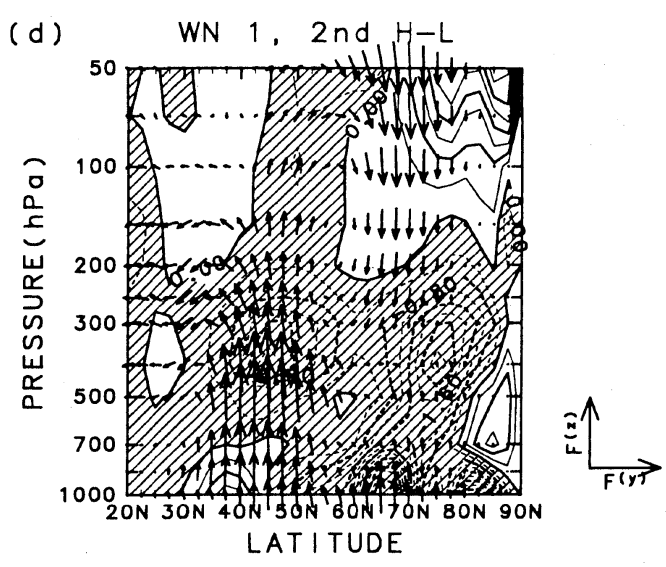

XUNIT $=6.667 \mathrm{E}-01, \mathrm{YUN} I T=6.667 \mathrm{E}-01$

CONTOUR INTERVAL $=4.000 E-01$

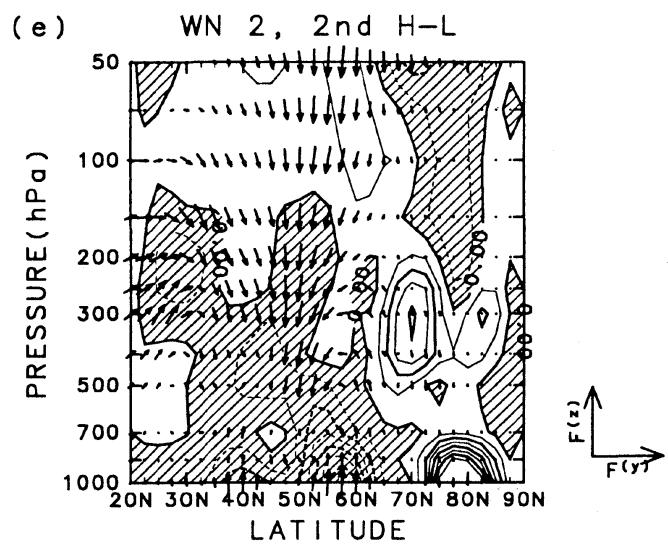

XUNIT $=6.667 \mathrm{E}-01$, YUNIT $=6.667 \mathrm{E}-01$

CONTOUR INTERVAL $=4.000 E-01$

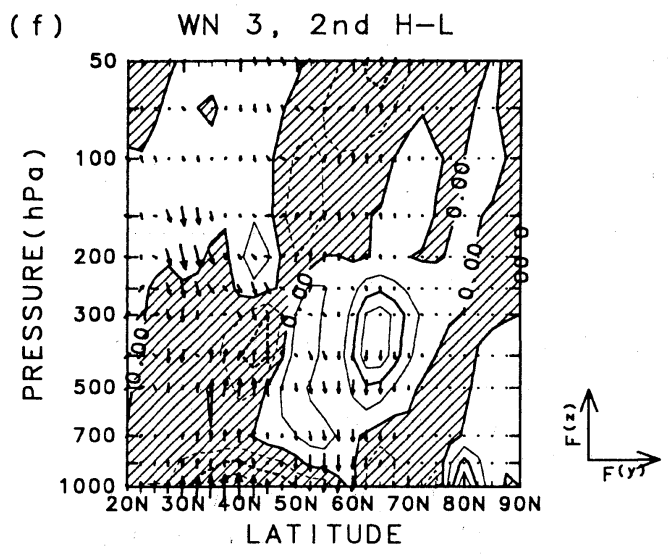

XUNIT $=6.667 E-01$, YUNIT $=6.667 \mathrm{E}-01$

CONTOUR INTERVAL $=4.000 E-01$

Fig. 9. As in Fig. 5, except for differences in the Eliassen-Palm (E-P) cross section for each planetary-scale wave. (a)-(c) Composed from the wavenumber 1-3 based on the first mode, respectively. (d)-(f) As in (a)-(c), but for the second EOF. Contours represent acceleration of the mean flow due to the E-P fluxes. Contour interval is $0.4 \mathrm{~ms}^{-1}$ day $^{-1}$. The length of the E-P flux vectors is multiplied by the factor $\exp (z / H)$, where $H$ is the scale height $\left(H=6.98 \times 10^{3} \mathrm{~m}\right)$. Unit vectors over the meridional and vertical components of E-P flux vectors are $6.7 \times 10^{15} \mathrm{kgms}^{-1}$ and $1.6 \times 10^{13} \mathrm{kgms}^{-1}$, respectively. 
(a)

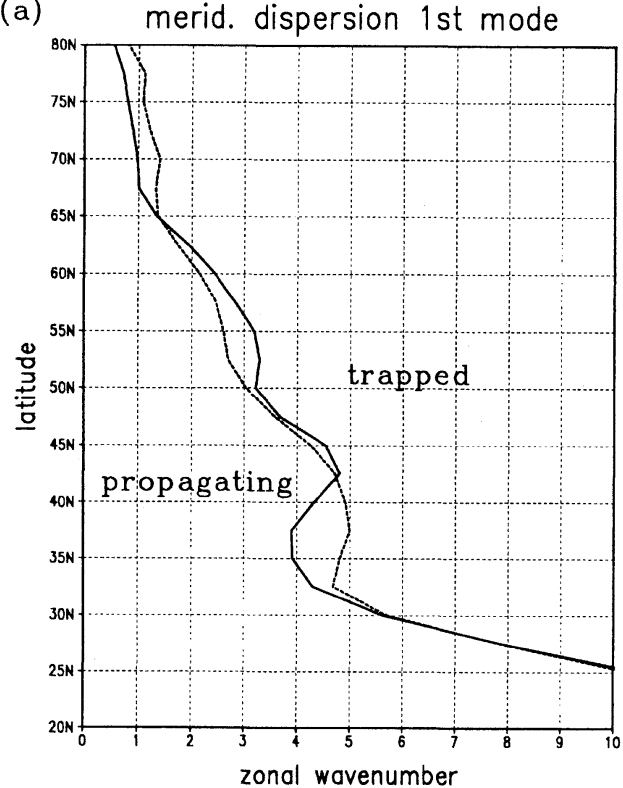

(b)

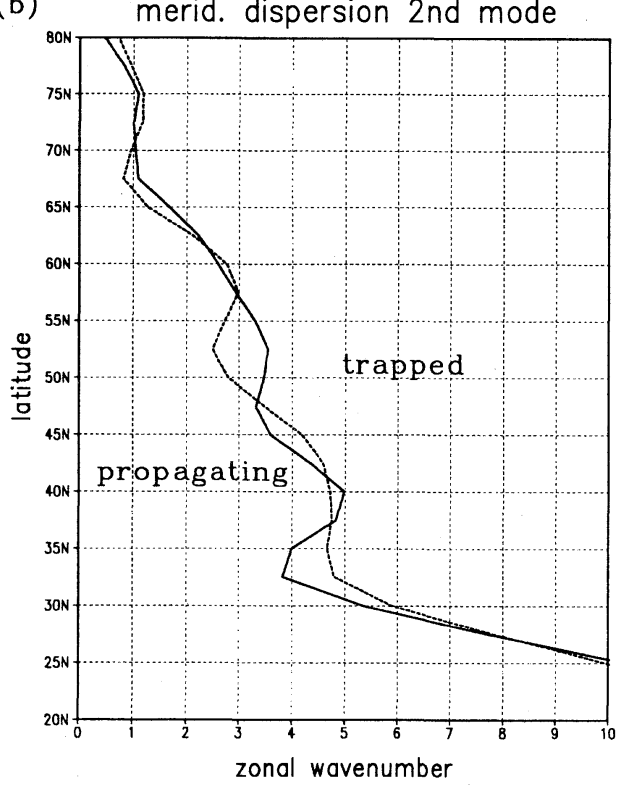

Fig. 10. The critical wavenumber $n_{s}=a k_{s}$ at $500 \mathrm{hPa}$ composed from (a) the first EOF and (b) the second EOF. The composite years are the same as in Fig. 5. The solid line represents high score years, while the dashed line represents low score years.

Once the equatorward wave activity is enhanced, the zonal wind profile should change to the favorable profile for equatorward propagation, which in turn enhances the equatorward propagation of the wave. This positive feedback over the North Atlantic and Eurasia seems to be a key factor, which makes the AO (PEA) or the EOF-1 EU mode the most dominant internal mode in the Northern Hemisphere ex-
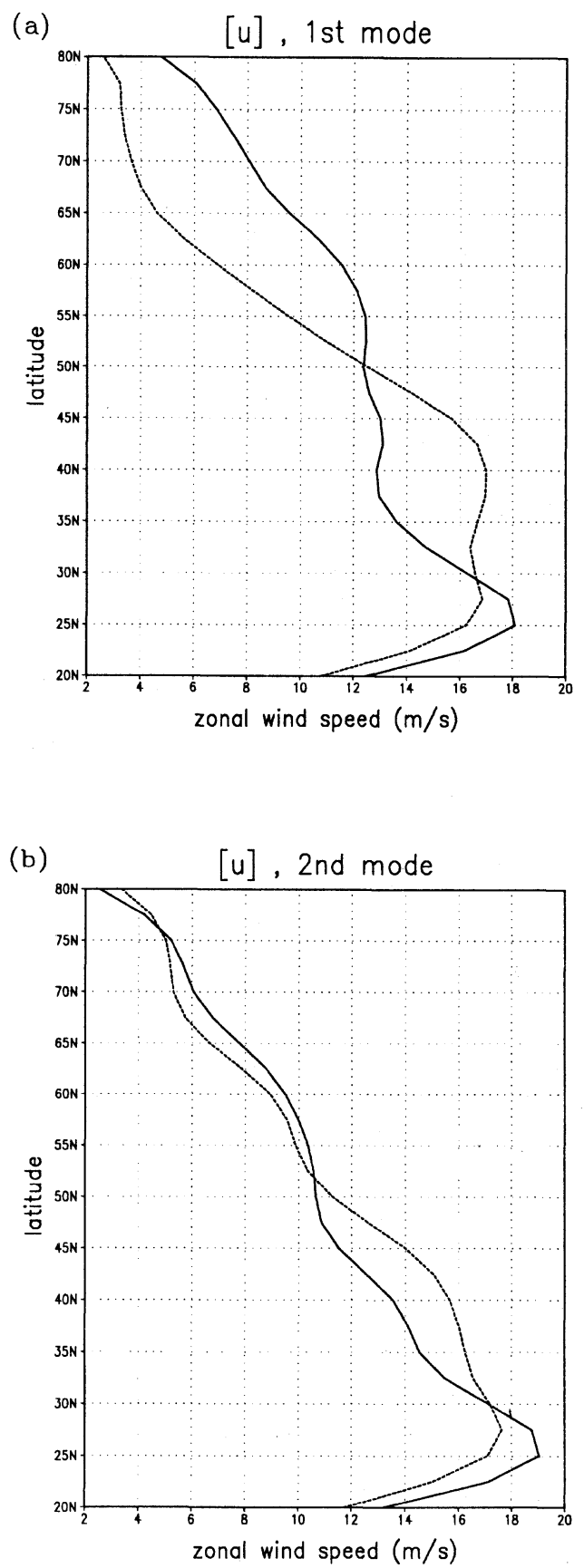

Fig. 11. As in Fig. 10, except for the meridional profile of zonal wind averaged over the region $60^{\circ} \mathrm{W}-150^{\circ} \mathrm{E}$.

tratropic atmosphere.

\subsection{Long-term variation of the two mode}

Because we identify two different EU patterns (Fig. 5, referred to as the EU1 and EU2, respectively), we define indices for these EU patterns in a similar manner to the original ones. The EU1 pattern - which is related to the first EOF - has multiple centers at $\left(70^{\circ} \mathrm{N}, 50^{\circ} \mathrm{W}\right),\left(50^{\circ} \mathrm{N}, 5^{\circ} \mathrm{W}\right),\left(50^{\circ} \mathrm{N}\right.$, $\left.55^{\circ} \mathrm{E}\right)$ and $\left(60^{\circ} \mathrm{N}, 115^{\circ} \mathrm{E}\right)$. The EU2 pattern - accompanied with the second EOF - also has multiple centers at $\left(45^{\circ} \mathrm{N}, 40^{\circ} \mathrm{W}\right),\left(70^{\circ} \mathrm{N}, 30^{\circ} \mathrm{W}\right),\left(65^{\circ} \mathrm{N}\right.$, 

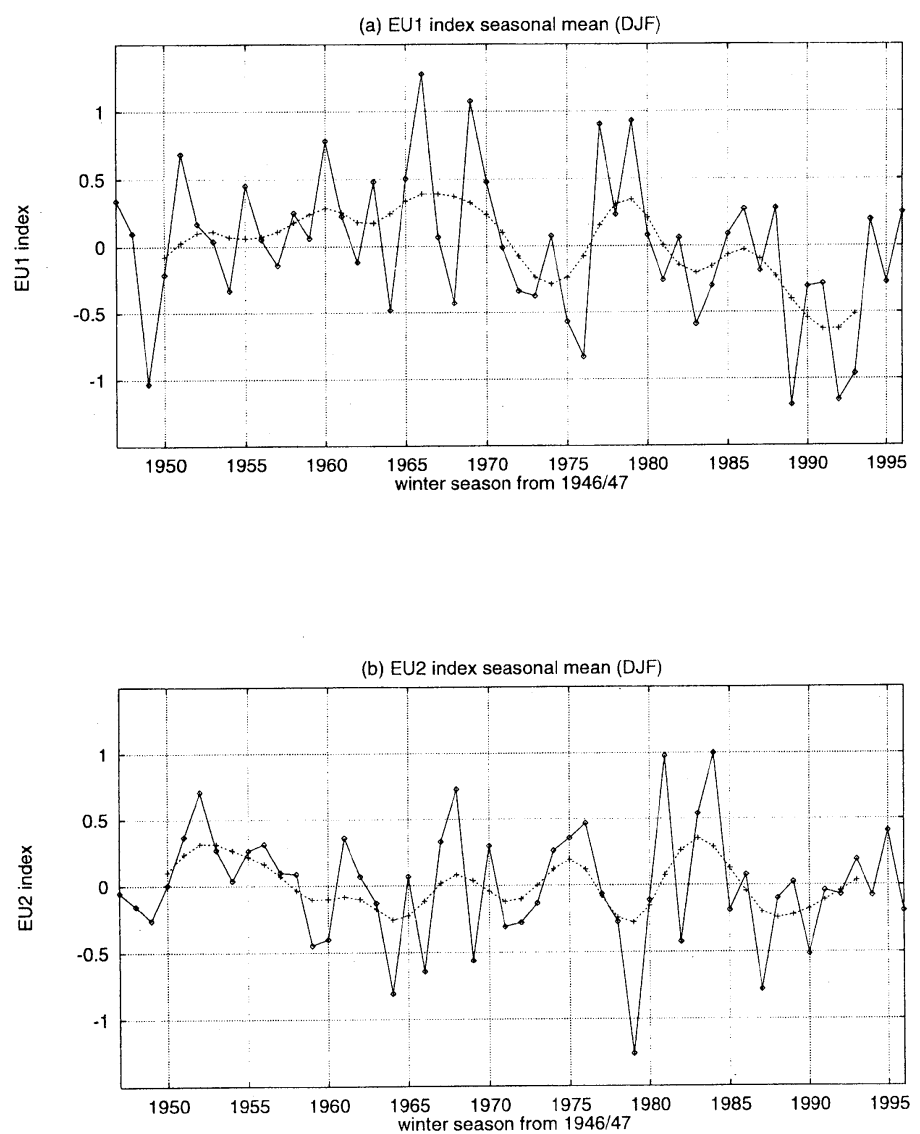

Fig. 12. Long-term variability of (a) the EU1 index and (b) the EU2 index defined in the text. The solid lines show the original data and the dashed lines indicate low-passed data as in Fig. 2.

Table 2. Correlation coefficients between the EU1, EU2 indices and EOF mode, EU original and $\mathrm{PC}$ indices. The symbols are the same as in Table 1.

\begin{tabular}{cccc}
\multicolumn{4}{c}{ correlation coefficient } \\
\hline & EOF mode & EU original & PC \\
\hline EU1 & $-0.95^{* *}$ & $0.33^{*}$ & $0.67^{* *}$ \\
EU2 & $0.89^{* *}$ & $0.53^{* *}$ & -0.06 \\
\hline
\end{tabular}

$\left.80^{\circ} \mathrm{E}\right)$ and $\left(40^{\circ} \mathrm{N}, 130^{\circ} \mathrm{E}\right)$. Note that we defined the negative EU1 as the pattern shown in Fig. 5a, and the positive EU1 as the reversed pattern. On the other hand, we defined the positive EU2 as the pattern shown in Fig. 5b, and the negative EU2 as the reversed pattern to produce the same polarity as the EU original index (Fig. 2a). Thus we define the EU1 and the EU2 indices as follows,

$$
\begin{aligned}
\mathrm{EU} 1= & \frac{1}{4}\left\{\mathrm{Z}^{*}\left(70^{\circ} \mathrm{N}, 50^{\circ} \mathrm{W}\right)-\mathrm{Z}^{*}\left(50^{\circ} \mathrm{N}, 5^{\circ} \mathrm{W}\right)\right. \\
& \left.+\mathrm{Z}^{*}\left(50^{\circ} \mathrm{N}, 55^{\circ} \mathrm{E}\right)-\mathrm{Z}^{*}\left(60^{\circ} \mathrm{N}, 115^{\circ} \mathrm{E}\right)\right\}, \\
\mathrm{EU} 2= & \frac{1}{4}\left\{\mathrm{Z}^{*}\left(45^{\circ} \mathrm{N}, 40^{\circ} \mathrm{W}\right)-\mathrm{Z}^{*}\left(70^{\circ} \mathrm{N}, 30^{\circ} \mathrm{W}\right)\right.
\end{aligned}
$$

$$
\left.+\mathrm{Z}^{*}\left(65^{\circ} \mathrm{N}, 80^{\circ} \mathrm{E}\right)-\mathrm{Z}^{*}\left(40^{\circ} \mathrm{N}, 130^{\circ} \mathrm{E}\right)\right\},
$$

where the symbol $Z^{*}$ denotes the same as in Eq. (1). One of the centers of action exists in Greenland in EU1, and the North Atlantic in EU2. Because each anomaly is large, we include these grid points as the centers of action of the two modified EU patterns.

Because the indices are calculated from the $500 \mathrm{hPa}$ geopotential height data having a longer record, we can study pattern variations back to winter 1947. Figure 12 shows the long term variability of the EU1 and EU2 indices. The correlation coefficients between the indices and the corresponding scores of EOF modes (Fig. 4) during the overlapping period from 1979 to 1994 , are -0.95 for the EU1 pattern and 0.89 for the EU2 pattern. Therefore, almost all the variations of the two modes are captured by these indices. The EU1 (Fig. 12a) includes a large recent abrupt shift, but the EU2 (Fig. 12b) has no shift in winter 1989. The correlation coefficients between the EU original index and the EU1 and EU2 indices are 0.33 and 0.53 (Table 2), which are significant at the 95 and $99 \%$ significance level, respectively. There is a remarkable difference between EU1 and EU2 in the correlation with the PC index. The correlation coefficient between the EU1 
and the PC index is 0.67 , which is significant at the $99 \%$ significance level. Whereas the correlation coefficient is -0.06 between the EU2 and the PC index. From this correlation analysis, we confirm that the EU1 pattern, which is obtained from the first mode of the EOF, is more related to the PC index variability. Applying the spectral analysis, we found that the EU1 has a peak at 13.3 years (not shown). The 13.3-year periodicity of the EU1 is close to the 10-year periodicity of the $\mathrm{PC}$ index, considering the coarse spectral resolution of the Blackman-Tukey method.

\section{Conclusions}

In this study we have focused on the EU pattern, which is associated with the resent abrupt change in the mid- and high-latitude circulations. We have clarified recent variability of the EU pattern by using NMC objective analysis and JMA data. It is found in this study that the phase of the EU pattern has reversed in the 1988/89 winter from positive to negative. The height field over the polar region has decreased since winter $1988 / 89$. That is consistent with the intensified polar vortex throughout the troposphere after 1988 (Tanaka et al., 1996; Walsh, 1996).

The wave activity flux was computed in order to evaluate the property of the stationary Rossby wave propagation. When the EU index is positive, the Rossby wave propagates directly from North Europe to East Asia. Whereas when it is negative, the direction of wave propagation is southeastward from North Europe to the Middle East.

From the results of the EOF analysis, it is evident that there are two leading modes in the variability of the wave activity flux related to the EU pattern. In the first mode, referred as EU1, we detected the southeastward flux pattern from the North Atlantic to the Middle East. The first mode pattern is connected with recent atmospheric change in the midhigh-latitude. In the second mode, the flux pattern is associated with the other teleconnection patterns. It is also found from correlation analysis, that both patterns are not related to SST over the tropical Pacific (not shown).

It is found from E-P flux and $\nabla \cdot \mathbf{F}$ composite maps based on the EOF results, that the wavenumber 3 Rossby wave plays an important role in the changes of zonal circulation due to the E-P flux divergences.

We confirmed by applying the meridional wave dispersion theory that in both modes the Rossby wave can propagate equatorward in high score winters. It is also found that the meridional profile of zonal wind plays an important role in meridional propagation of the Rossby wave. The wind profile, in turn, is modified by the wave activity. This positive feedback is a key factor that makes the EU1 mode one of the most dominant internal modes in the northern winter.

\section{Acknowledgments}

We thank the members of the Division of Ocean and Atmospheric Sciences, Graduate School of Environmental Earth Science, Hokkaido University for their helpful discussions and comments, and two anonymous reviewers for improving the original manuscript. Thanks are also extended to $\mathrm{H}$. Yoshimura and Y. Kuroda of the MRI for providing the JMA $500 \mathrm{hPa}$ geopotential height data.

\section{References}

Barnston, A.G. and R.E. Livezey, 1987: Classification, seasonality and persistence of low-frequency atmospheric circulation patterns. Mon. Wea. Rev., 115, 1083-1126.

Blackmon, M.L., Y.-H. Lee and J.M. Wallace, 1984: Horizontal structure of $500 \mathrm{mb}$ height fluctuations with long, intermediate and short time scales. J. Atmos. Sci., 41, 961-979.

Esbensen, S.K., 1984: A comparison of intermonthly and interannual teleconnections in the $700 \mathrm{mb}$ geopotential height field during the Northern Hemisphere winter. Mon. Wea. Rev., 112, 2016-2032.

Held, I.M., 1983: Stationary and quasi-stationary eddies in the extratropical troposphere: theory, Largescale dynamical processes in the atmosphere, edited by B.J. Hoskins and R. Pearce, 127-168, Academic Press.

Horel, J.D., 1981: A rotated principal component analysis of the interannual variability of the Northern Hemisphere $500 \mathrm{mb}$ height field. Mon. Wea. Rev., 109, 2080-2092.

Hoskins, B.J. and D.J. Karoly, 1981: The steady linear response of a spherical atmosphere to thermal and orographic forcing. J. Atmos. Sci., 38, 1179-1196.

Hsu, H. and J.M. Wallace, 1985: Vertical structure of wintertime teleconnection patterns. J. Atmos. Sci., 42, 1693-1710.

Hurrell, J.W., 1995: Decadal trends in the North Atlantic Oscillation: Regional temperatures and precipitation. Science, 269, 676-679.

Kodera, K., M. Chiba, H. Koide, A. Kitoh and Y. Nikaidou, 1996: Interannual variability of winter stratosphere and troposphere in the northern hemisphere. J. Meteor. Soc. Japan, 74, 365-382.

Koide, H. and K. Kodera, 1997: Characteristics of the recent long-term wintertime variability in the atmosphere and oceans. Tenki, 44, 535-550 (in Japanese).

Lau, N.-C. and M.J. Nath, 1996: The role of the 'atmospheric bridge' in linking tropical Pacific ENSO events to extratropical SST anomalies. J. Climate, 9, 2036-2057.

Nitta, T. and S. Yamada, 1989: Recent warming of tropical sea surface temperature and its relationship to the northern hemisphere circulation. J. Meteor. Soc. Japan, 67, 375-383.

Plumb, R.A., 1985: On the three-dimensional propagation of stationary waves. J. Atmos. Sci., 42, 217229 . 
Tanaka, H.L., R. Kanohgi and T. Yasunari, 1996: Recent abrupt intensification of the northern polar vortex since 1988. J. Meteor. Soc. Japan, 74, 947-954.

Thompson, D.W.J. and J.M. Wallace, 1998: The Arctic Oscillation signature in the wintertime geopotential height and temperature fields. Geophys. Res. Lett., 25, 1297-1300.

Ting, M., M.P. Hoerling, T. Xu and A. Kumar, 1996: Northern Hemisphere teleconnection patterns during extreme phases of the zonal-mean circulation. J. Climate, 9, 2614-2633.

Trenberth, K.E., 1990: Recent observed interdecadal climate changes in the northern hemisphere. Bull. Amer. Meteor. Soc., 71, 988-993.

Trenberth, K.E. and J.W. Hurrel, 1994: Decadal atmosphere-ocean variations in the Pacific. Clim. Dyn., 9, 303-319.

Trenberth, K.E., G.W. Branstator, D. Karoly, A.
Kumar, N.-C. Lau and C. Ropelewski, 1998: Progress during TOGA in understanding and modeling global teleconnections associated with tropical sea surface temperatures. J. Geophys. Res., 103, 14291-14324.

Wallace, J.M. and D.S. Gutzler, 1981: Teleconnections in the geopotential hight field during the northern hemisphere winter. Mon. Wea. Rev., 109, 784-812.

Wallace, J.M., C. Smith and Q. Jiang, 1990: Spatial patterns of atmosphere-ocean interaction in the northern winter. J. Climate, 3, 990-998.

Walsh, J.E., W.L. Chapman and T.L. Shy, 1996: Recent decrease of sea level pressure in the central Arctic. J. Climate, 9, 480-486.

Watanabe, M. and T. Nitta, 1999: Decadal changes in the atmospheric circulation and associated surface climate variations in the Northern Hemisphere winter. J. Climate, 12, 494-510.

\section{ユーラシアパターンの変動と活動度フラックスを用いた解釈 \\ 大橋康昭・山崎孝治 1 \\ (北海道大学大学院地球環境科学研究科)}

テレコネクションパターンの一つであるユーラシア $(\mathrm{EU})$ パターンについて、近年の変動と定常波の 活動度フラックスとの関係について解析を行った。その結果、1988/89 年の冬季を境に、極渦の強化と同 時に EU インデックスの符号が正から負に逆転していることがわかった。EUパターンのメカニズムにつ いて詳細に調べるために、定常波の活動度フラックスを計算した。EU インデックスが正のときは、ロス ビー波がヨーロッパから東アジアにかけて直接伝播しているのに対して、EU インデックスが負のときは、 ヨーロッパから中東へ南東に伝播していることがわかった。

そこで、ユーラシア大陸上のロスビー波の変動について明らかにするために、活動度フラックスに対し て $\mathrm{EOF}$ 解析を行った。その結果、 $\mathrm{EU}$ パターンと関連した 2 つの卓越モードが検出された。第 1 モード は極域高度場の変動と結び付いた $1988 / 89$ 年冬季の大気場のシフトに関連していた。第 2 モードは NAO やPNA といった他のテレコネクションパターンと関連したモードであった。

卓越モードの出現について、wave forcingによる带状風の変化とロスビー波の子午線方向への伝播特 性を調べることによって解釈された。その結果、第 1 モードの波数 3 成分が帯状風の変化に重要な役割を 果たしていることがわかった。また、子午線方向の帯状風プロファイルは活動度フラックスの構造と一致 していた。この EUパターンに関連した活動度フラックスと帯状風との間に見られる正のフィードバック が、第 1 モードが卓越する要因となっていることがわかった。 